\title{
Recrutando rockers: festivais de música como mediadores da disseminação da cultura do rock na sociedade angolana
}

\author{
Melina Aparecida dos Santos Silva' \\ https://orcid.org/0000-0003-1773-8493
}

I - PUC-RS

Porto Alegre (RS). Brasil

Resumo: O artigo investiga como os festivais gratuitos de rock, O Rock Lalimwe Eteke Ifa (ORLEI) e Rock no Rio Catumbela, realizados nas cidades do Huambo e da Catumbela, em Angola, consistem em uma das principais formas de circulação e contato de moradores locais com o gênero musical rock, no período de desenvolvimento econômico, político e social estabelecido com o fim da guerra, em 04 de abril de 2002. A etnografia aborda como os festivais de rock angolanos atuam como facilitadores do contato do público local com a cultura do gênero musical, em que performances ao vivo do movimento do rock angolano apresentam suas convenções técnicas, de comportamentos e de vestuários nesses espaços de entretenimento.

Palavras-chave: festivais de rock; Angola; Rock no Rio Catumbela; Rock Lalimwe Eteke Ifa

Abstract: Recruiting rockers: Music Festivals Mediation as a means to spreading the rock culture in Angolan society - The paper addresses how free rock festivals, Rock Lalimwe Eteke Ifa (ORLEI) and Rock no Rio Catumbela, held in the cities of Huambo and Catumbela, in Angola, are one of the main forms of circulation, consumption and contact of local residents with the rock music genre in this period of economic, political and social development established with the end of the war in April 04, 2002. This ethnography discusses how Angolan rock festivals act as facilitators of the contact of the local public with the culture of the music genre, in which live performances of the Angolan rock movement present their technical conventions, behaviors and costumes in these entertainment spaces.

Keywords: Rock festivals; Angola; Rock no Rio Catumbela; Rock Lalimwe Eteke Ifa 


\section{Introdução}

Festivais de música têm sido abordados por geógrafos e turismólogos baseando-se no papel do desenvolvimento econômico e nas estratégias de turismo regional como fonte de atratividade de visitantes e de geração de empregos para comunidades locais (ACCORDIA; WHITFORD, 2006; CONNEL; GIBSON, 2012).

As dinâmicas culturais dos festivais de música são mapeadas em pesquisas sobre esferas públicas, de contestação social e de memória histórica, de experiências musicais (GIORGI \& SASSATELLI; DELANTY, 2011; VILARINO, 2002; HERSCHMANN, 2010; QUINN, 2003; TJORA, 2016).

Outro foco de pesquisas acadêmicas seria a inclusão social por meio dos festivais de música e como produtores culturais facilitam o acesso da comunidade local à programação musical com a criação de entradas gratuitas (LAING; MAIR, 2015). Contudo, essas investigações abordam eventos realizados em territórios rurais e urbanos em países e comunidades com poder aquisitivo e com infraestrutura de patrocinadores, planejamento turístico etc. O objetivo aqui é observar como festivais de música são pontes para inclusão social em histórias locais de restrição aos meios financeiros e tecnológicos. O artigo investiga como os festivais gratuitos de rock, O Rock Lalimwe Eteke Ifa (ORLEI) e Rock no Rio Catumbela, realizados nas cidades do Huambo e da Catumbela, em Angola, consistem em uma das principais formas de circulação e de contato de moradores com o rock.

De acordo com os interlocutores da pesquisa, o início do rock em Angola coincide com o crescimento urbano e econômico de cidades como Luanda e Benguela, a reestruturação econômica de Portugal, durante o regime ditatorial de Antonio Oliveira Salazar, em meados dos anos 1950 e, posteriormente, com os movimentos de libertação da colônia portuguesa. Nos anos 1960, bandas de rock possuíam jovens militares portugueses enviados para Angola para defender a metrópole, conterrâneos portugueses e moradores angolanos consumidores de rock. Bandas locais tocavam versões de canções anglófonas, como Beatles, sem a pretensão de reproduzi-las de forma fiel (CORREIA, 2017; MONTEIRO, 2013).

Shows de rock em Angola eram realizados em instituições como Cinema Restauração, em Luanda, e concursos de bandas, realizados nas capitais angolana, Luanda, e portuguesa, Lisboa. Entre as bandas atuantes no período e que gravaram álbuns, temos Os Rocks e Duo Ouro Negro. Programas de rádio como Hora dos Jovens e Angola 2.0 eram os espaços de divulgação do rock, na década de 1960 (CORREIA, 2017).

Programas culturais da Televisão Pública de Angola (TPA) e Canal C (atual Rádio Nacional de Angola), na década de 1970, divulgavam bandas de rock internacionais, como Dire Straits e os brasileiros Erasmo e Roberto Carlos. Angola obteve independência em 11 de novembro de 1975, após 15 anos de luta armada contra o colonialismo português. Esse processo de transição política seria rompido pelas divergências entre os três grupos, 
levando ao início de um conflito interno entre MPLA e UNITA, já que FNLA dissolveu-se logo em seguida. Nas eleições gerais em setembro de 1992, o presidente da UNITA, Jonas Savimbi, não aceitou a vitória do MPLA, a qual elegeu José Eduardo dos Santos, dando início a novos conflitos armados ${ }^{1}$.

Na década de 1990, bandas de rock, como Mutantes e Acromaníacos, formaramse nas trocas de afinidades musicais e nos laços sociais criados nos ambientes escolares como Escola Portuguesa e IML-MAKARENCO, ambas em Luanda. Outras formações, como Anexos e Metal Tomb, foram criadas por amigos, vizinhos e parentes. O contato desses jovens com o rock aconteceu sob mediação de familiares, amigos e vizinhos que viajavam ao exterior, como Portugal e África do Sul. Essas mediações eram fontes de acesso a instrumentos e às técnicas musicais. O movimento musical surgido nos ambientes escolares obteve uma queda com a migração de instrumentistas para Portugal, África do Sul e Espanha para cursar o Ensino Superior, no fim dos anos 1990.

A guerra terminou em 2002, com a vitória do MPLA (PEARCE, 2016). Parte dos instrumentistas de rock atuantes na década anterior retornaram para Angola, constituindo novas formações com os rockers que permaneceram no país, e demais instrumentistas dessa nova geração. Em um cenário de desenvolvimento da indústria fonográfica e das mídias locais, a cultura do rock possui a mediação de programas de rádio, como Volume 10 (96.5 FM) e Muzangola Rock (Luanda Antena Comercial).

A partir de trabalhos de campo realizados com o movimento do rock angolano, em três períodos diferentes de 2014, 2016 e 2017, observei como os dois maiores festivais de rock locais, ORLEI e Rock no Rio Catumbela, atuam como mediadores do contato do público local com a cultura do rock. Entre suas fontes de mediação (OROZCO-GOMEZ, 1991) temos as performances ao vivo, as convenções técnicas, de comportamentos e de vestuários em diálogo com os códigos culturais do gênero musical (FRITH, 1997).

\section{Metodologia}

Para realização desta etnografia, três trabalhos de campo foram realizados nos anos de 2014, 2016 e 2017 nas cidades Luanda, Benguela, Huambo e Catumbela, locais de concentração de integrantes e de eventos do movimento do rock angolano. Acompanhei ensaios, shows ao vivo, duas sessões de gravação do álbum do grupo Dor Fantasma, participei de interações dos rockers angolanos nos grupos online Amigos dos Dor Fantasma, Kavalera Entertainment, Cube Records e Movimento de Divulgação e Apoio ao Rock em Angola, de projetos de divulgação do rock, como o programa Volume 10, e a editora fonográfica Cube Records, na qual continuo como colaboradora até os dias atuais. Realizei 22 entrevistas com bandas locais, com quatro produtores de eventos da rede musical,

1 MPLA: Movimento Popular pela Libertação de Angola. UNITA: União Nacional para a Independência Total de Angola. FNLA: Frente Nacional pela Libertação de Angola. 
Carlos Bessa (Rock no Rio Catumbela), Sònia Ferreira (ORLEI), Manel Kavalera e Marcos Ferraz (Kavalera Entertainment), dois produtores musicais especializados na captação do rock, Tiago Oliveira e António Barrote, dois radialistas dos programas de rádio Volume 10 (96.5 RFM) e Muzangola Rock (Luanda Antena Comercial), Luís Fernandes e Toke É Esse, respectivamente ${ }^{2}$.

Sigo a teoria de mediação de Jesús Martín-Barbero e das abordagens do campo comunicacional latinoamericano. Barbero (1997) redireciona o olhar científico dos meios às mediações, apontando "uma mediação fundamental entre a sociedade e as proposições da mídia de massa: a inserção cultural do receptor" (BRAGA, 2012, p. 32). Desta forma, a perspectiva de Barbero privilegiaria "os sujeitos e não mais as instituições midiáticas, suas tecnologias" e os produtos da indústria cultural (SILVA, 2012, p.108).

Barbero, em leituras posteriores, aborda as mediações a partir de dois tipos de relações, sendo uma entre matrizes culturais e formatos industriais e a outra entre lógicas de produção e de dinâmicas de recepção e de consumo cultural (SILVA, 2012, p.108). Porém, a teoria das mediações possui críticas, como a dificuldade de definição do que seria mediação, podendo ser de prática teórica, discursiva, cultural, econômica e institucional (SIGNATES, 2003), até a predominância do viés sociológico em relação ao comunicacional (SILVA, 2012).

Orozco Gómes (1991) procura ultrapassar as dicotomias apresentadas na teoria das mediações, conectando variadas fontes de mediação como cultura, política, classe social, etnia, gênero, idade, os meios, os movimentos sociais (SIGNATES, 2003). Em sua ação de organizar múltiplos cenários e contatos em que o processo de recepção circula, Orozco Gómes apresenta as mediações individual, situacional, institucional e videotecnólogica (BARROS; LOPES, 2015).

Com a música ao vivo, rockers procuram aproximar a comunidade da cultura do rock e do movimento musical angolano, como descrito pelo então baixista da banda Ovelha Negra, Yannick Matos: "Estamos em uma fase de recrutamento". Portanto, os rockers têm criado alternativas para "fazer com que as pessoas ouçam, ouçam e ouçam sem parar as bandas" (Entrevista realizada em Luanda, em setembro de 2017).

\section{Os festivais como base do movimento do rock angolano}

A produção de festivais de rock, no período de pós-guerra civil, teve como primeira iniciativa o Rock Fora de Stock, nos dias 30 e 31 de maio de 2009, em uma fazenda localizada a $7 \mathrm{~km}$ da capital Huambo. A ideia do festival surgiu ao acaso, durante uma conversa informal dos músicos Zé Beato e Wilker Flores sobre shows ao vivo. Com

2 Bandas entrevistadas foram Acromaníacos, Before Crush, Black Soul, Dor Fantasma, Horde of Silence, Kosmik, Last Shout, Lunna, Instinto Primário, ex-integrantes das bandas Metal Tomb, Múmias e Neblina, Mutantes, M’vula, Ovelha Negra, Projectos Falhados, Singra, Silent Whisper, Sentido Proibido, Still Rolling With Times,

Tiranuz, Zé Beato e os Desempregados. 
o apoio de Sónia Ferreira, coordenadora da ONG Okutiuka, o evento foi financiado pelos três amigos e obteve a participação de seis bandas locais, como Fios Eléctricos, Zé Sanjambela e Zé Beato.

Nas origens de produção de festivais de rock, os rockers observaram que as plateias eram compostas, em sua maioria, por moradores da zona rural do Huambo, com pouco contato com o rock, como analisado por Zé Beato:

Foi engraçado é que o pessoal da cidade, quando viu os panfletos pela cidade falou: "vou", mas ninguém foi. Quem encheu aquele espaço foi o pessoal do kimbo. Quando eles ouviram a música, eles saíram todos das ombalas e ficou uma cena muito fixe, principalmente, durante a performance do Zé Sanjambela, que canta música em umbundu³. O povo entendeu perfeitamente o que ele tava falando, porque eles falam mais ou menos português (Entrevista realizada no Huambo, em setembro de 2014).

Da experiência com a produção do Rock Fora de Stock, surgiu o Rock Lalimwe Eteke Ifa (ORLEl), em maio de 2011. O título do festival escolhido por Sónia Ferreira e Wilker Flores significa "o rock nunca vai morrer" em umbundu, uma forma de homenagear a história local e de aproximar os moradores com a cultura do rock. Com previsão da nona edição para 2019, o ORLEI tem a organização de Sónia Ferreira com apoio do vocalista da banda Kishi, Manel Kavalera, do baixista da banda Instinto Primário, Yuri Almeida, do vocalista e guitarrista do grupo Zé Beato e Os Desempregados, Zé Beato, e do radialista Toke É Esse. Entre os patrocinadores do ORLEl, estão as cervejarias Cuca e Doppel, o Governo Provincial do Huambo, empresas locais de pequeno e médio porte, como a Tipografia Corimba.

As edições do ORLEI de 2012 a 2016 ocorreram na semana do aniversário da cidade do Huambo, dia 21 de setembro, no pavilhão Osvaldo Serra Van Dúnem. Devido aos fatores climáticos, como fortes chuvas no período, as duas datas foram transferidas para final de agosto e início de setembro. Em 2018, o festival foi deslocado para um terreno em frente ao aeroporto Albano Machado, no centro do Huambo.

Uma das ideologias que caracterizam o movimento do rock angolano é o Do It Yourself. A ética "Faça Você Mesmo" (Do It Yourself, em inglês) continua a ser debatida entre os participantes e pesquisadores da rede musical do punk rock e suas definições são constantemente modificadas e ampliadas pelos atores sociais (HOLTZMAN et al, 2007). "Do It Yourself consiste na ideia de que você pode fazer por conta própria as atividades normalmente reservadas para a produção capitalista (em que os produtos são criados para consumo em um sistema que incentiva a alienação e a não participação)" (HOLTZMAN et al, 2007, p. 45). Logo, a ética DIY seria "algo fundamentalmente feito pelos fãs para os fãs" (MORAN, 2010, p. 45).

3 Fixe: Legal. Kimbo: Conjunto de moradias localizadas nas zonas rurais do interior de Angola. Ombala: Pequenas aldeias ou povoados na língua umbundu. Umbundu: língua bantu falada pelos povos ovimbundo, localizados nos territórios ao centro de Angola. 
O DIY tem sido abordado em pesquisas como uma ética de produção cultural underground - em contraposição à hegemonia de conglomerados midiáticos e de suas obras mainstream. A lógica DIY do movimento do rock angolano consiste nas formas de organização de eventos, na gravação de álbuns, na construção de meios underground de circulação e de distribuição, como plataformas e revistas online, e na criação de home studios, como Estúdio 2, e de editoras fonográficas, como Cube Records.

Uma das dinâmicas do underground/DIY seria a de que os atores sociais concentram variados papéis sociais no processo de produção, de circulação e de consumo da música, interações inseridas na produção do ORLEI como um todo em comparação ao Palco Rock do Rock no Rio Catumbela. Durante a produção do ORLEl, acompanhei as interações das bandas para identificar os equipamentos musicais que seriam compartilhados, como amplificadores. O operador de áudio Yuri Almeida pediu que as bandas levassem suas melhores marcas de microfones, que também seriam usados na captação de instrumentos musicais, como as guitarras. Os bateristas foram informados para levarem os pratos com melhores condições, visto que os patrocinadores informaram que não possuíam unidades disponíveis para o evento.

O envolvimento dos rockers nas etapas de produção do ORLEl e do Rock no Rio Catumbela apontam para o que Campbell nomeia de consumo artesal (2004). Campbell (2010) sugere que os cientistas sociais direcionem o olhar para a existência dos consumidores que se engajam em um ato artesanal de consumo. Desta forma, o autor procura demonstrar as práticas de consumo em que o objeto é "em essência, percebido como sendo idealizado e fabricado pela mesma pessoa" (CAMPBELL, 2010, p. 45). Portanto, consistiria em uma forma de consumo artesanal em que o consumidor "empresta suas habilidades, conhecimento, discernimento e paixão ao ser motivado por seu desejo de se expressar" (CAMPBELL, 2010, p. 46).

Embora o Rock no Rio Catumbela seja maior na estrutura do que o ORLEl, a produção do Palco Rock possui semelhanças com o festival Rock Huambo na lógica Do It Yourself de sua organização: o baixista da banda Instinto Primário, Yuri Almeida, atua como operador de áudio nos dois festivais; a direção de palco é realizada pelo baterista das bandas Horde of Silence e Kishi, Yannick Merino. A apresentação do line-up do Palco Rock é atribuída aos radialistas do programa Volume 10, Luís Fernandes e Yara Paz. Já o Palco Mundo é apresentado pelo radialista da emissora privada Luanda Antena Comercial, Toke é Esse.

Ambos os festivais proporcionam aos participantes uma percepção de cenas musicais (STRAW, 2015; WALLACH; LEVINE, 2012) construída pela atuação de músicos amadores, pelos espaços de performances ao vivo, pelas trocas de informações entre os participantes, como apontado por Sónia Ferreira:

As bandas vão tocar no mesmo palco que as bandas mais experientes e isso fará com que elas também ganhem mais experiência tanto no palco quanto na 
música. Isso faz parte de um dos objetivos do ORLEl: ajudar no crescimento das bandas, divulgar o rock e fazer com o que rock seja também um estilo de música ouvido em Angola. Como não há outros espaços para as bandas irem, normalmente elas são descobertas pelo ORLEI (Entrevista realizada em Benguela, em outubro de 2017).

Logo, entre as contribuições do ORLEl para a comunidade, temos o espaço de contato com o gênero musical e a construção de uma cultura do rock através da programação com 10 a 15 bandas nacionais e de outros países africanos, como Botsuana e Moçambique ${ }^{4}$. Na opinião de Sónia Ferreira: "Hoje, temos bandas no ORLEI que, em 2011, eram miúdos, deveriam ter 11 ou 12 anos e agora estão tocando. Se o ORLEI não tivesse sido realizado, talvez não estavam nem ouvindo rock hoje" (Entrevista realizada em Benguela, em outubro de 2017).

Já a produção do Rock no Rio Catumbela possui a parceria da cervejaria Soba Catumbela, sob a supervisão do diretor comercial Jorge Arrulo, e do sócio do selo fonográfico Cube Records, Carlos Bessa, produtor do Palco Rock. O Rock no Rio Catumbela foi idealizado como um pequeno evento musical para homenagear a mudança da Catumbela de distrito para município no dia 05 de outubro de 2011. Logo, os dois dias de festival acontecem na semana de comemoração do aniversário da cidade.

A proposta do Rock no Rio Catumbela era promover bandas de rock locais para um público formado, "em sua maioria, por pessoas que não são próximas do gênero musical", como explicado por Carlos Bessa. Contudo, formações nacionais - e de outros países do continente africano, como África do Sul e Quênia - têm atuado para aproximar a comunidade local do metal ${ }^{5}$. A partir da quarta edição, em 2016, a estrutura do festival foi ampliada com divisão do line-up em dois palcos, com 10 atrações cada um: Mundo, dedicado à música angolana e supervisionado pelo produtor James Titelman, e Rock, com atrações nacionais e internacionais escolhidas pela equipe da Cube Records, com Carlos Bessa, eu e o baterista Yannick Merino, desde $2017^{6}$.

4 A programação do ORLEI 2017 foi composta predominantemente por bandas de rock locais e de heavy metal internacionais: Still Rolling With Times, Sentido Proibido, Black Soul, Dor Fantasma, Projectos Falhados, Beside, Amosi Just a Label (música angolana), Zé Beato (reggae), Overthrust DeathMetal (metal/ Botsuana), The Dreamers, Ovelha Negra.

5 A programação do Palco Rock 2017 foi Afogados (rock), Projectos Falhados (rock), Zé Beato (reggae), Rish (pop/ rock - Nairóbi - Quênia), Amosi (música angolana), Basicantes (rock), Sentido Proibido (rock-metal), Black Soul (Luanda), Pop Show Band (covers de clássicos do rock), M'vula (rap-rock-metal), Sistas of Metal (heavy metal, Joanesburgo - África do Sul), Dor Fantasma (metal). Os Djs Manel Kavalera e Henda Slash (programa Volume 10) foram os responsáveis pelo fechamento dos dois dias de festival. Já o Palco Mundo teve Boto Trindade (música angolana), Eva Rap Diva (rap), Ndaka Yo Wini \& Teddy Nsgingui (música angolana), Ricardo Lemvo (música angolana), Dji Tafinha (rap), Anabela Aya (música angolana), Angelo Boss \& Jorge Mulumba (música angolana) e Jorge Rosa (música angolana).

6 Música angolana agrega práticas musicais criadas nos espaços urbanos, como semba, inicialmente ligada aos discursos nacionalistas e de valorização da cultura tradicional (MOORMAN, 2005). Contudo, nos dias atuais, kizomba e kuduro também são inseridos no rótulo musical (KUSCHICK, 2016). Kuschick (2016, p. 148-149) alega que após o fim da guerra colonial, em 1975, uma nova geração de músicos angolanos começou a compor canções mais "dançantes e contagiantes, desconectadas de mensagens políticas". Essas canções possuíam influências de estilos musicais originados em países africanos como o Congo. Eduardo Paim e Paulo Flores são exemplos de artistas da rede musical. Kuduro consiste em um estilo de música eletrônica e dança local, influenciado pelo rap e pelo zouk. 
Embora acreditasse que o título do festival era uma referência ao festival brasileiro Rock in Rio e à sua edição em Portugal, Rock in Rio Lisboa, o produtor Carlos Bessa mencionou que a criação do evento possui outras motivações distanciadas de uma réplica do festival originado no Brasil. Isso porque o título do festival faria menção ao nome do rio da Catumbela. Com a programação em Palco Rock e Palco Mundo, mudança empreendida pela direção comercial da Soba Catumbela, em 2016, as referências às matrizes brasileiras de produção de festivais ficaram evidentes a ponto de Bessa declarar que "neste caso, já é uma cópia do Rock in Rio".

Os participantes dos festivais possuem faixa etária de 10 a 50 anos, sendo de ambos os gêneros sexuais e predominantemente do fenótipo negro. De forma geral, a renda dos participantes seria de categoria média-baixa ${ }^{7}$. Laing \& Mair (2015) apontam que os objetivos sociais dos produtores de festivais giram em torno da facilitação de acesso aos espetáculos, com a oferta de ingressos gratuitos e descontos em entradas para as populações com menor poder aquisitivo, e da ampliação da tolerância e da diversidade em suas programações culturais.

Argumentos de "engajamento político" enunciados pelos produtores de festivais de música, como narrativas de "mudança social" e da "interação social" mediada pelas atrações culturais (LAING; MAIR, 2015) foram apresentadas, em uníssono, pelos rockers. Ressalto que os rockers criam pequenos eventos para inserir a comunidade local na cultura do rock, casos observados em bairros periféricos de Luanda, do Lobito e de Benguela, como Rock no Gueto, Festival do Bairro da Luz e Ombaka Rock Festival.

Ambos os festivais possuem a área VIP e a zona de acesso geral aos shows. Contudo, a área VIP do Rock no Rio Catumbela possui um setor de venda de ingressos para entrada nas festas de encerramento com atuação de DJs ${ }^{8}$. Parte dos ingressos consiste em cortesia para empresários locais, representantes políticos e contatos comerciais da Soba Catumbela. Logo, há uma tentativa de inclusão da comunidade nos eventos e uma tensão entre os objetivos comerciais e sociais do festival (LAING; MAIR, 2015).

Já a área VIP do ORLEl concentra as bandas escaladas na programação, integrantes do movimento musical, a equipe de produção do festival, parceiros da organização e convidados como jornalistas e amigos dos produtores e das bandas locais, sem a cobrança de entrada. O ORLEI tem sido descrito pelos rockers como um "verdadeiro" festival de rock, orientado pelos preceitos underground em sua organização e programação, como elencado por Zé Beato:

Huambo é a capital do rock em Angola. O ORLEI, para mim, é o melhor festival, independente da dimensão que os outro festivais tenham: de todo o aparato

7 O Banco Mundial reclassificou Angola para país de renda média-baixa, que se situa entre 1.006 e 3.955 dólares norte-americanos por habitante. Para saber mais: https://observador.pt/2017/07/24/banco-mundial-desceclassificacao-de-angola-para-renda-media-baixa/

8 A área VIP possui custo de 5000 kwanzas (em torno de R\$60 na cotação do dia 28 de fevereiro de 2019). 
técnico, de todo o dinheiro envolvido na organização dos festivais, o ORLEl é o único festival realmente de rock. Os outros festivais têm rock no alinhamento, mas não são festivais de rock. Não apenas por isto. Huambo é a cidade que melhor recebe o pessoal, não há preconceitos, todo mundo está interessado em conhecer, em ouvir, em saber, existe abertura para isso tudo. Então, é a nossa capital, é a capital dos rockers (Entrevista realizada em Benguela, em outubro de 2017).

Huber (2016) interpreta a metáfora do mainstream a partir de seu significado como uma força natural e autêntica, a qual seria contaminada pelos riachos que trafegam para construir o fluxo principal (HUBER, 2016). Portanto, o imaginário do mainstream reflete esse modo de produção cultural como "homogêneo" (HUBER, 2016, p.10), como demonstrado no relato de Carlos Bessa:

Às vezes, sofremos acusações que me deixam um pouco magoado: "ah, vocês se venderam!". Isto é uma coisa muito comum no metal: "Venderam-se! Vocês colocam no festival bandas que não têm a ver com rock". Mas, em relação a isto, sou muito pragmático na vida. (...) Uma tática, que foi usada no segundo ano do festival e no terceiro também, foi colocar um kudurista para fechar cada uma das noites. Fomos muito criticados por isto! O que é certo é que as pessoas aguentaram cinco, seis horas de bandas de rock e de metal à espera dos kuduristas. Certamente, destas 5.000 ou 6.000 pessoas que estavam lá a ouvir o kudurista, certamente, dessas 5.000 ou 6.000 pessoas, algumas delas passaram a gostar de rock e vão voltar, no ano seguinte, pelo rock e não pelos kuduristas (Entrevista realizada por Skype, em maio de 2016).

O underground consiste em uma rede de normas e de funções específicas que contribuem para o funcionamento deste mercado musical de caráter autônomo e restrito (CAMPOY, 2012). Embora Campoy (2012) reforce o argumento binário entre mainstream e underground, sua reflexão nos ajuda a compreender como as classificações real (underground e sua relação afetiva com o rock-metal) e falso (mainstream e sua busca pelo lucro) representam as regras de funcionamento do underground e atuam como defesa deste espaço (CAMPOY, 2012).

Mesmo com a inserção da agência de publicidade de Benguela, POPYA Comunicação, para a campanha de marketing e a contratação de equipamentos e de técnicos de som da Rádio Vial, empresa de sonorização localizada em Luanda, não podemos compreender suas dinâmicas com os binarismos mainstream e underground. O Palco Rock possui uma estrutura mainstream de equipamentos e de financiamentos e a produção e práticas musicais underground.

\section{Não é um público rocker?}

Ao contrário da expectativa de que os públicos de festivais teriam como principal motivo de participação a experiência musical (BOWEN \& DANIELS, 2005), os sujeitos 
procuram interações sociais e escapismo da rotina, como diversão com a família e amigos, conhecer pessoas com afinidades musicais ou ampliar o repertório musical. As "práticas de festivais" (TJORA, 2016) oferecem mudanças de comportamentos dos participantes com o acúmulo de experiências de edições anteriores, como elencado pelo apresentador do Palco Rock, Luís Fernandes:

Nós temos de ser realistas: no ORLEl e na Catumbela, noventa por cento, e estou a ser muito amigo, não é público rocker. Nesses locais, como não acontece nada, eles veem a publicidade e falam: "vamos para lá". Agora também temos de ser realistas: é bom que eles vão lá ver, porque isso também vai permitir que eles criem uma cultura. Na realidade, o ORLEl e o Rock no Rio Catumbela estão fazendo um ótimo trabalho, pois estão, de alguma forma, mudando as mentes das pessoas de que realmente existe rock em Angola. Se as mesmas pessoas, que não gostavam de rock, forem todos os anos lá, elas já podem começar a se identificar. Portanto, isto é um outro caminho que está a ser trilhado. Mas, dizer que o rock está bem é uma utopia! (Entrevista realizada em Luanda, em outubro de 2016).

Embora os rockers comentem que os moradores locais possuam pouco contato com o rock, ORLEI realizou a oitava edição em 2018 e o Rock no Rio Catumbela, a quinta edição em $2017^{9}$. A continuidade desses festivais tem impulsionado as práticas culturais do rock e aproximado as comunidades do movimento musical. Tenho observado que as audiências não se dispersam nas performances ao vivo, independente do gênero musical adotado pelas formações ou de suas motivações de presença nos festivais, como ressaltado pelo baterista da banda Horde of Silence, Yannick Merino, após a participação no Rock no Rio Catumbela, em 2017:

Acho que o pessoal aqui da Catumbela é, digamos, o mais receptivo de todos os sítios que já toquei. Eles recebem bem aqui qualquer tipo de banda, não sei se por falta de divertimento...Não importa se é metal, se é pop, se é kuduro, eles aderem. Uma das coisas que posso te dizer que é para louvar o pessoal daqui: pode até ficar vazio, mas não fica menos de 100 pessoas no público. Eu fiquei espantado ontem porque fomos tocar e tinha mais de 90 pessoas (risos)! (Entrevista realizada em Benguela, em outubro de 2016).

As pessoas localizadas na área geral dos festivais reagiam às performances musicais com gritos e com palmas. Nas edições do ORLEl e do Rock no Rio Catumbela posteriores, percebi que o público cantava coletivamente os refrões de canções de bandas como Ḿv vula, Amosi Just a Label e Zé Beato. Frith (1997) descreve a importância da mediação do corpo na fruição musical, referindo-se não apenas à execução musical, mas também a como a performance é recebida e avaliada pelo público. Logo, a performance é um processo

9 A sexta edição do Rock no Rio foi transferida para o ano de 2019, devido a problemas econômicos do único patrocinador do festival, a cervejaria Soba Catumbela. 
comunicativo, uma forma de retórica de gestos, baseado na corporeidade e uma experiência de interação social, com normas negociadas através de gêneros musicais e do público.

Uma performance é considerada pela audiência e pelas bandas bem-sucedida quando o show se torna "uma atração irresistível na consciência de seu público" (BERGER, 1999, p. 44). Nesses cenários, os significados das experiências musicais, como "diversão, energia e a sexualidade" (BERGER, 1999, p.44), são projetados para o público e são reproduzidos pelas audiências na forma destas respostas corporais, como gritos, os moshings e os headbanguings ${ }^{10}$.

Essas respostas corporais esperadas de um público de rock estavam presentes na área VIP, demonstrando o espaço de concentração de pessoas inseridas nas convenções sonoras, temáticas e comportamentais do gênero musical. A área VIP concentrava atores sociais com poder de compra de produtos culturais do rock, como camisas de bandas e formatos musicais. Para obter camisas de bandas não oficiais, por exemplo, rockers angolanos compram itens importados do Brasil, de Portugal e da Tailândia, em viagens ao exterior ou, em certos casos, em lojas locais ${ }^{11}$. O parque industrial angolano demanda novas políticas públicas para ampliação de indústrias de bens de consumo.

Durante a programação do Palco Mundo, o mestre de cerimônias Toke É Esse mencionou o caráter "elitista" da área VIP ao sugerir os tipos de interações para as audiências: "As pessoas do público podem bater palmas! O resto da área VIP pode sacudir as joias!"12.

Embora as respostas corporais do rock não estejam disseminadas na audiência geral, os públicos têm demonstrado formas de afinidade com as bandas locais, como o caso de um participante que tirou a camisa no meio da performance da banda Sentido Proibido, na edição de 2017 do ORLEI. O participante gritou para o vocalista Nilzo imitá-lo, pedido replicado pelos presentes. O pedido remete ao Rock no Rio Catumbela 2016, quando Nilzo tirou a camisa durante a estreia da banda no Palco Rock.

\section{Conclusão}

O artigo abordou os festivais de música gratuitos como uma das fontes de mediação da cultura do rock no contexto social angolano. Observei que os festivais de rock oferecem dinâmicas próprias de comunicação e de interação com suas práticas culturais, como as performances musicais e as respostas corporais de seus públicos, a sensação de pertencimento temporária a um grupo social heterogêneo que pode - ou não - compartilhar gostos musicais e comportamentos específicos.

10 Banguear consiste em um movimento coordenado da cabeça com o tempo e o andamento musicais. Mosh é uma resposta corporal esperada de públicos de rock, a qual destaca o corpo e maneiras variadas de contato físico, incluindo colisões, empurrões.

11 As camisas de bandas não oficiais, em Angola, chegam a custar de 3 a 10 mil kwanzas (R\$36 a R\$121 em cotação do dia 14 de maio de 2019), de acordo com interlocutores da pesquisa.

12 A referência de Toke é Esse consiste na declaração de John Lennon, durante um show beneficente da Royal Variety Performance, em que se dirigiu para o público com a seguinte ideia: "Para nosso último número, eu queria pedir a ajuda de vocês. As pessoas nos assentos baratos podem bater palmas. O resto de vocês pode sacudir as joias". 
Os festivais de rock ampliaram a diversidade em suas programações, com artistas da música angolana para atrair as comunidades locais. Essa decisão dos produtores culturais revelou os valores sociais de modos de produção e de circulação mainstream e underground e, consequentemente, uma procura de distinção e de fronteiras identitárias dos rockers - possivelmente - em relação à música angolana. Contudo, essa atitude política "anti-corporações midiáticas mainstream" (MORAN, 2010) que, inclusive, envolve o DIY, precisará ser esclarecida com os rockers em trabalhos de campo futuros. Embora o DIY seja definido como "algo feito pelos fãs para fãs" (MORAN, 2010), no caso de Angola, os rockers criam obras musicais e eventos com o engajamento de fãs para alcançar comunidades locais não necessariamente fãs de rock.

Pesquisar os festivais de rock em Angola demonstrou que suas atividades não estariam isoladas culturalmente da circulação mundial do gênero musical. Uma das fontes de mediação do rock em Angola seriam os laços sociais primários e secundários. Amigos, familiares, vizinhos e os rockers em viagens internacionais para Portugal, Brasil, África do Sul e Botsuana, por exemplo, acumulam conhecimentos, habilidades e produtos da cultura do rock. O caráter artesanal de consumo dos rockers insere expectativas e convenções técnicas e visuais adquiridas em dinâmicas locais e internacionais, permitindo que suas práticas estejam conectadas com os códigos culturais do rock mundial.

Melina Aparecida dos Santos Silva é pós-doutoranda e professora colaboradora no Programa de Pós-Graduação em Comunicação na PUC-RS. É doutora pelo Programa de Pós-Graduação em Comunicação da Universidade Federal Fluminense (UFF).

melsantos1985@gmail.com

\section{Referências}

ACCORDIA, C.; WHITFORD, M. Festival attendance and development of social capital. Journal of Convention \& Event Tourism, 8:2, 1-18, 2006.

BARROS, L.; LOPES, M. Mediações, midiatização e estética da recepção nos debates sobre educomunicação. Vozes e Diálogo, v. 14, p. 229-241, 2015.

BERGER, H. Metal, Rock and Jazz. Perception and the Phenomenology of Musical Experience. Hanover: University Press of New England, 1999.

BOWEN, H.; DANIELS, M. Does the music matter? Motivations for attending a music festival. Event Management, 9 (3), 2005.

BRAGA, J. L. Circuitos versus campos sociais. In: MATTOS, M. A.; JANOTTI JUNIOR, J.; JACKS, N., orgs. Mediação \& midiatização [online]. Salvador: EDUFBA, 2012. 
CAMPBELL, C. O Consumidor Artesão: Cultura, Artesania e Consumo em uma Sociedade PósModerna. Antropolítica, n. 17, pp. 45-67, 2004.

CAMPOY, L. Trevas sobre a luz: O underground do Heavy Metal Extremo no Brasil. São Paulo: Alameda, 2012.

CORREIA, J. Beto dos windies: beto kalulu: Da cena musical em Luanda à consagração no Algarve. Lisbon: Ideias com História, 2017.

FRITH, S. Performing Rites: on the value of popular music. Cambridge: Harvard University Press, 1998.

GIBSON, C.; CONNEL, J. Music festivals and regional development in Australia. England \& United States: Ashgate, 2012.

GIORGI, L.; SASSATELLI, M.; DELANTY, G. Festivals and the Cultural Public Sphere. London \& New York: Routledge, 2011.

HOLTZMAN, B. et al. Do It Yourself...And the movement beyond Capitalism. In: SHUKAITIS, S.; GRAEBER, D; BIDDLE, E. (eds). Constituent Imagination: Militant Investigations/collective Theorization. Oakland: AK Press, 2007.

HERSCHMANN, M. Crescimento dos festivais de música independente no Brasil. In: SÁ, S. P. (org.). Rumos da cultura da música. Porto Alegre: Sulinas, pp. 267-304, 2010.

HUBER, A. Mainstream as a Metaphor: Imagining Dominant Culture. In: BAKER, S.; BENNET, A.; TAYLOR, J. Redefining Mainstream Popular Music. Londres \& New York: Routledge, 2013.

KUSCHICK, M. Kotas, mamás, mais velhos, pais grandes do semba: música angolana nos fluxos do atlântico negro. 2016. Campinas, São Paulo. Tese de Doutorado. Etnomusicologia. Universidade de Campinas.

LAING, J; MAIR, J. Music festivals and social inclusion - The festival's organizer's perspective, Leisure Sciences, 37: 3, 252-268, 2015.

MARTIN BARBERO, J. Dos meios às mediações: comunicação, cultura e hegemonia. Rio de Janeiro: Editora UFRJ, 1997.

MOORMAN, M. Intonations: A Social History of Music and Nation in Luanda, Angola, from 1945 to Recent Times. Ohio: Ohio University Press, 2008.

MORAN, I. Punk: The Do-It Yourself Subculture. Social Sciences Journal, 10 (1), 2010.

MONTEIRO, T. Tudo isto é pop: portugalidades musicais contemporâneas entre a tradição e a modernidade. Rio de Janeiro: Editora Caetés, 2013.

OROZCO GÓMEZ, G. Recepción televisiva: tres aproximaciones y uma razón para su estudio. Cuadernos de Comunicación y Praticas Sociales. México D.F., México, n. 2, 1991.

QUEIRÓS, A. A experiência nos festivais de música. Dissertação (Mestrado). 117f. Instituto Superior de Contabilidade e de Administração da Universidade de Aveiro. 2016.

QUINN, B. Symbols, practices and myth-making: cultural perspectives on the Wexford Festival Opera. Tourism Geographies, 5(3), 329-349, 2013.

PEARCE, J. A Guerra Civil em Angola 1975-2002. Lisboa: Tinta da China, 2017.

SIGNATES, L. Estudo sobre o conceito de mediação e sua validade para como categoria de análise para os estudos de Comunicação. Novos Olhares, n. 12, $2^{\circ}$ semestre 2003.

SILVA, G. Pode o conceito reformulado de bios midiático conciliar mediações e midiatização? In: MATTOS, M. A.; JANOTTI JUNIOR, J.; JACKS, N. (Orgs). Mediação \& midiatização [online]. Salvador: EDUFBA, 2012. 
STRAW, W. Some Things a Scene Might Be. Cultural Studies, v. 29, n. 3, pp.476-485, 2015.

TJORA, A. The social rhythm of the rock music festival. Popular Music, v. 35, n. 1, pp. 64-83, 2016.

VILARINO, R. A MPB em movimento - Música, festivais e censura. 4 ed. São Paulo: Olho D’Água, 2002.

WALLACH, J.; LEVINE, A. I want you to support local metal: A theory of metal scene formation. Popular Music History, Sheffield, v. 6, n. 1, p. 116-134, mar. 2011.

Artigo recebido em 28/02/2019

e aprovado em 08/07/2019. 